\title{
Peran Mediasi Komitmen Organisasional pada Pengaruh Kepuasan Kerja terhadap Kinerja Dosen Tetap Universitas Swasta di Kota Medan
}

\author{
The Mediating Role of Organizational Commitment on the Effect of \\ Job Satisfaction on the Performance of Permanent Lecturers \\ of Private University in Medan City
}

\author{
Muhammad Adhan $^{1)}$, Jufrizen ${ }^{2)}$, Muhammad Andi Prayogi ${ }^{3)}$, Yudi Siswadi ${ }^{4)}$ \\ ${ }^{1,2,3,4)}$ Fakultas Ekonomi dan Bisnis, Universitas Muhammadiyah Sumatera Utara, Medan \\ e-mail korespondensi: jufrizen@umsu.ac.id
}

\begin{tabular}{|l|}
\hline Info Artikel \\
\hline Riwayat Artikel : \\
Diterima: 21 Oktober 2019 \\
Disetujui: 28 November 2019 \\
Dipublikasikan: Januari 2020 \\
\hline Nomor DOI \\
10.33059/jseb.v11i1.1654 \\
Cara Mensitasi : \\
Adhan, M., Jufrizen, Prayogi, \\
M.A. \& Siswadi, Y. 2020. \\
Peran Mediasi Komitmen \\
Organisasional pada Pengaruh \\
Kepuasan Kerja terhadap \\
Kinerja Dosen Tetap di \\
Universitas Swasta di Kota \\
Medan. Jurnal Samudra \\
Ekonomi dan Bisnis. \\
11(1): 1-15.
\end{tabular}

\begin{abstract}
Abstrak
Penelitian ini bertujuan untuk menganalisis pengaruh kepuasan kerja terhadap komitmen dan kinerja organisasi dosen, dan untuk menganalisis peran mediasi dari komitmen organisasi terhadap pengaruh kepuasan kerja terhadap kinerja dosen. Penelitian ini dilakukan di Universitas Muhammadiyah Sumatra Utara (UMSU) dan Universitas Muslim Nusantara (UMN) Al Washliyah di Medan. Populasinya adalah 425 dosen tetap yang memiliki jabatan fungsional di kedua universitas tersebut, dan sampel ditentukan sebanyak 219 orang. Data dikumpulkan dengan teknik wawancara dan kuesioner. Analisis jalur digunakan untuk menganalisis data, dan menunjukkan bahwa kepuasan kerja terbukti memiliki pengaruh langsung yang signifikan baik terhadap komitmen organisasi maupun terhadap kinerja dosen. Komitmen organisasi juga terbukti berpengaruh secara langsung dan signifikan terhadap kinerja. Namun demikian. hasil pengujian menunjukkan bahwa kepuasan kerja tidak mendukung kinerja dosen ketika dimediasi melalui komitmen organisasi.
\end{abstract}

Kata Kunci: Kepuasan Kerja, Komitmen Organisasional, Kinerja Dosen.

\section{Article Info \\ Article History : \\ Received: 21 October 2019 \\ Accepted: 28 November 2019 \\ Published: January 2020}

\section{DOI Number :}

10.33059/jseb.v11i1.1654

How to cite :

Adhan, M., Jufrizen, Prayogi, M.A. \& Siswadi, Y. 2020.

Peran Mediasi Komitmen

Organisasional pada Pengaruh

Kepuasan Kerja terhadap

Kinerja Dosen Tetap di

Universitas Swasta di Kota

Medan. Jurnal Samudra

Ekonomi dan Bisnis.

11(1): 1-15.

\section{Abstract}

This study aims to analyze the effect of job satisfaction on lecturer organizational commitment and performance, and to analyze the mediating role of organizational commitment to the effect of job satisfaction on lecturer performance. This research was conducted at the Universitas Muhammadiyah Sumatera Utara (UMSU) and the Universitas Muslim Nusantara (UMN) Al Washliyah in Medan. The population is 425 permanent lecturers who hold functional positions at the two universities, and the sample was determined as many as 219 people. Data were collected by interview and questionnaire techniques. Path analysis is used to analyze data, and shows that job satisfaction is proven to have a significant direct effect both on organizational commitment and on lecturer performance. Organizational commitment is also proven to have a direct and significant effect on performance. However. the test results show that job satisfaction does not support lecturer performance when mediated through organizational commitment.

Keywords: Job Satisfaction, Organizational Commitment, Lecture Performance. 


\section{PENDAHULUAN}

Perguruan tinggi swasta sebagai sebagai bagian dari sistem pendidikan nasional perlu terus didorong untuk berupaya memperkuat kemampuan jajaran civitas akademikanya agar menjadi lebih profesional dan berkualitas (Trisnaningsih, 2011). Keberhasilan yang dicapai perguruan tinggi ditentukan oleh akuntabilitas yang tinggi dari dosen dan kemampuan untuk melakukan tugas-tugas Universitas Tri Dharma. Tiga fungsi dosen di Universitas Tri Dharma meliputi Pengajaran, Penelitian, dan pengembangan masyarakat (Gunawan et al., 2018). Anggraeni (2013) menyatakan dosen yang melaksanakan tugas utama Universitas Tri Dharma adalah melalui publikasi karya ilmiah yang dilakukan secara internal oleh dosen sendiri dan dari luar lingkungan akan meningkatkan kinerja dosen. Dosen yang melakukan penelitian melalui publikasi karya tulis ilmiah adalah salah satu upaya meningkatkan kemampuan dosen (Sukirno \& Siengthai, 2011).

Kinerja dosen di suatu perguruan tinggi dapat dipengaruhi kepuasan kerja. Istilah kepuasan kerja di sini mengacu pada apa yang dosen rasakan tentang pekerjaan mengajar mereka. Kepuasan kerja dosen dapat secara signifikan mempengaruhi aspek kehidupan kampus terkait dengan komitmen organisasi dan kinerja mereka (Gunawan et al., 2018). Studi tentang komitmen organisasi dosen merupakan salah isu strategis, karena mobilitas dan tingkat keluar masuknya dosen berpengaruh terhadap kualitas pendidikan. Dosen di perguruan tinggi yang memiliki komitmen tinggi terhadap institusinya akan terus berupaya untuk mengembangkan diri guna meningkatkan kualitas mengajar, yang akhirnya akan menunjang pengembangan perguruan tinggi tersebut di masa depan.

Perguruan tinggi memainkan peran penting dalam pembangunan sosial, ekonomi, politik dan budaya suatu negara. Setiap perguruan tinggi di Indonesia tidak akan dapat mencapai sasaran dan tujuannya tanpa staf akademik yang efisien dan berkomitmen. Masalah komitmen dosen di universitas telah menarik perhatian publik, pendidik, seta pemangku kepentingan lainnya dalam bidang pendidikan. Hal ini dikarenakan komitmen organisasi dalam menghasilkan kinerja dan efektivitas kerja yang lebih baik. Oleh karena itu, agar sistem perguruan tinggi mencapai tujuan menghasilkan tenaga kerja yang sangat terampil untuk memenuhi kebutuhan sosialekonomi bangsa, komitmen staf akademik harus mendapat perhatian khusus (Akpan, 2013). Rendahnya komitmen organisasi dosen kepada institusinya merupakan salah satu kerugian pada perguruan tinggi, sekaligus kepada diri pribadi dosen tersebut.

Sementara para ahli menyatakan bahwa komitmen karyawan terhadap organisasi merupakan faktor yang harus dimiliki oleh setiap anggota organisasi, karena komitmen terhadap organisasi diyakini merupakan satu pendorong bagi karyawan untuk serius dalam bekerja sehingga dapat memenuhi target kerja yang diberikan kepadanya (Meyer et al., 2002; Yousef, 2000).

Kinerja dan komitmen organisasi di dosen berada di bawah pengaruh kepuasan kerja. Hal ini sejalan dengan gagasan Reyes dan Shin (1995) yang menyatakan bahwa kepuasan kerja dosen adalah faktor kunci dalam komitmen dosen dan terkait dengan retensi dosen. Whiteford (1990) telah mengidentifikasi beberapa indikator kepuasan dosen terhadap pekerjaannya dan rasa keberhasilan, termasuk hubungan positif dengan rekan kerja, kondisi kerja yang memuaskan dan prestise dan harga diri sehubungan dengan proses pengajaran ( $\mathrm{Na}$ et al., 2011). Karyawan yang memiliki kepuasan kerja berarti dia sedmikian mencintai pekerjaannya; hal itu membuatnya tetap bekerja dan tidak mudah bosan (Arifin, 2012). 
Ketidakpuasan dosen dapat menurunkan level komitmen mereka pada institusi. Akhirnya, institusi harus menghadapi kerugian karena kepergian dosen karena tingkat ketidakpuasan mereka (Ahmad et al., 2015).

Berdasarkan pengamatan atas fenomena kompetensi dosen ditemukan fakta bahwa pengetahuan dosen tentang mata pelajaran yang diajarkan masih rendah dan dinilai tidak sesuai dengan orientasi kualitas, keterampilan pemecahan masalah, keterampilan perencanaan, kerja tim, dan kapasitas belajar mandiri. Sebagai hasil dari kompetensi yang masih rendah menyebabkan adanya kepuasan kerja, komitmen organisasi dosen dan penurunan kinerja. Hal yang sama juga dapat dilihat bahwa kepuasan kerja dosen dalam mengajar belum menunjukkan kepuasan seperti yang diharapkan. Banyak dosen yang mengeluhkan rendahnya pemberian remunerasi dalam bentuk kompensasi untuk posisi karier yang ditempati, tidak mendapat perbaikan kondisi kerja seperti yang diharapkan dalam usaha mendukung kariernya, jarang memperoleh promosi jabatan sesuai pangkat dan jabatan fungsional, serta tidak adanya kesempatan untuk mengembangkan pekerjaan di bidang pendidikan tinggi.

Beberapa penelitian terdahulu menemukan adanya faktor-faktor yang mempengaruhi kinerja. Hasil penelitian milik Werang dan Agung (2017) serta Chalim (2018) menemukan bahwa kepuasan kerja berpengaruh terhadap kinerja, namun tidak sejalan dengan hasil penelitian milik Narasuci et al. (2018) yang menyatakan bahwa kepuasan kerja tidak berpengaruh terhadap kinerja dosen. Hasil penelitian Bangun et al. (2018) serta Gunawan et al. (2018) menujukkan bahwa kepuasan kerja juga berpengaruh terhadap komitmen organisasi. Namun temuan berbeda diperoleh hasil penelitian Anisykurlillah et al. (2013) yang menunjukkan kepuasan kerja tidak berpengaruh atas komitmen organisasi.
Selanjutnya hasil penelitian de Araújo dan Lopes (2014) serta Romadhona dan Wahyuningtyas (2019) menunjukkan bahwa komitmen organisasi berpengaruh terhadap kinerja, namun tidak sejalan dengan hasil penelitian Hidayati dan Rahmawati (2016) serta Eliyana et al. 2019) yang membuat kesimpulan bahwa komitmen organisasi tidak berpengaruh terhadap kinerja.

Beberapa perbedaan hasil yang terdapat dalam penelitian-penelitian terdahulu tersebut menunjukkan adanya research gap, sehingga perlu dilakukan kajian penelitian mengenai hubungan antara faktor-faktor tersebut diatas dengan kinerja. Berdasarkan hasil telaah gap itu maka penelitian ini menganalisis pengaruh langsung dari kepuasan kerja baik terhadap komitmen organisasional maupun kinerja dosen, serta bagaimana peran komitmen organisasional dalam memediasi pengaruh kepuasan kerja terhadap kinerja dosen.

\section{Kinerja Dosen}

Memahami kinerja sebagai salah satu istilah yang banyak digunakan dalam studi ilmiah manajemen sumber daya manusia, Kaplan dan Norton (2006) menyatakan bahwa kinerja adalah hasil maksimum aktualisasi dalam mencapai tujuan organisasi. Tujuannya adalah untuk memberikan pemahaman bahwa pekerjaan apapun yang dicapai merupakan perwujudan aktualisasi dari individu ataupun sekelompok orang yang melakukan kegiatan. Koontz dan Weihrich (2010) mengartikan kinerja adalah kegiatan berkesinambungan dalam menghasilkan tujuan. Kinerja adalah tahapan pencapaian suatu pekerjaan tertentu (Simanjuntak, 2011). Muchinsky dan Howes (2019) mendefinisikan kinerja pekerjaan yaitu seperangkat perilaku karyawan yang dapat diukur, dipantau, dan dievaluasi.

Sementara itu, Santos et al. (2018) mendefinisikan kinerja adalah kemampuan seseorang untuk melakukan kegiatan yang 
berkontribusi pada pengembangan inti teknis organisasi. Kinerja mengacu pada perilaku yang relevan dengan tujuan organisasi dan bisa diukur berdasarkan kontribusi mereka terhadap efektivitas organisasi (Kartini et al., 2017).

Keberhasilan lembaga pendidikan bisa dilihat dari kinerja dosen. Kinerja dosen merupakan kemampuan dosen bersangkutan untuk melaksanakan pekerjaan atau tugas yang diemban dan memiliki kemampuan menyelesaikan pekerjaan (Trisnaningsih, 2011). Pengukuran kinerja dosen menurut Wijatno (2009) mengacu pada Tridharma Pendidikan Tinggi, yaitu melaksanakan pendidikan dan pengajaran, penelitian dan penulisan makalah ilmiah, serta pengabdian kepada masyarakat.

\section{Komitmen Organisasional}

Baldwin dan Baldwin (2009) menyatakan komitmen organisasional merupakan komitmen yang nampak bukan loyalitas pasif, tetapi melibatkan hubungan aktif dengan organisasi. Komitmen organisasional yaitu komitmen teman sejawat ke atas namun bukan hanya menjadi loyalitas pasif, tetapi untuk berpartisipasi hubungan aktif dengan organisasi).

Luthans (2010) menyatakan definisi dari komitmen organisasi sebagai perwujudan dari totalitas loyalitas individu terhadap identitas organisasi. Komitmen organisasional dari karyawan merupakan kekuatan yang diyakini mengikat seseorang untu bersedia melakukan tindakan yang relevan dengan satu atau lebih target (Imran et al., 2014). Wu dan Norman (2006) menganggap komitmen organisasi sebagai totalitas dari kesetiaan orientasi nilai pada organisasi. Robbins dan Judge (2011) mendefinisikan komitmen organisasi sebagai tahap di mana karyawan mengenali kelompok tertentu dengan tujuan, dan berharap dapat tetap mempertahankan status sebagai anggota kelompok.

Komitmen organisasional diidentifikasi sebagai ikatan psikologis antara pekerja dan organisasi dengan memiliki kesetiaan pada, memiliki keinginan untuk terlibat, dan menjadi kurang rela meninggalkan organisasi (Griffin et al., 2009). Selain itu, Luthans (2010) mendefinisikan komitmen organisasi sebagai: (1) kesediaan yang kuat untuk tetap sebagai anggota kelompok; (2) kesediaan bekerja keras sebagai aspirasi organisasi; dan (3) kesediaan tertentu untuk menerima nilai dan tujuan organisasi. Curtis dan Wright, 2001) menyatakan bahwa komitmen organisasional terdiri dari tiga kelompok dimensi, yaitu: (1) Keinginan untuk mempertahankan keanggotaan dalam organisasi; (2) Keyakinan dan penerimaan nilai-nilai dan tujuan organisasi; serta, (3) Kesediaan untuk bekerja keras sebagai bagian dari organisasi.

Menurut Luthans (2010), terdapat tiga komponen komitmen organisasional, yaitu komponen afektif, komponen normatif dan komponen kontinyu. David dalam Sopiah (2008) mengemukakan tiga (3) faktor yang berpengaruh terhadap komitmen organisasi, yaitu faktor personal, karakteristik pekerjaan dan pengalaman kerja.

Karyawan yang berkomitmen tinggi pada organisasinya cenderung akan lebih bertanggungjawab (He et al., 2012). Komitmen organisasi dapat menjadi faktor yang bermanfaat bagi perilaku dan hasil kerja karyawan dan peredam tingkat turnover dalam suatu organisasi (Rose et al., 2009).

\section{Kepuasan Kerja}

Kepuasan kerja mengacu pada tingkat respons afektif yang diungkapkan oleh individu menunjukkan seberapa besar mereka menyukai pekerjaan mereka dalam hal seberapa banyak pekerjaan memenuhi kebutuhan mereka (Spector, 2009). Kreitner 
dan Kinicki (2013) mendefinisikan kepuasan kerja sebagai konstruk global atau sebagai konstelasi dimensi berbeda di mana karyawan bereaksi secara efektif.

Kepuasan kerja adalah tingkat kepuasan individu bahwa mereka mendapatkan manfaat yang sepadan dari berbagai aspek situasi kerja organisasi dimana tempat mereka bekerja (Tangkilisan, 2005). Kepuasan kerja juga dinyatakan sebagai perasaan dan sikap tentang pekerjaan (Schultz \& Schultz, 2015). Kepuasan kerja menurut Furnham et al. (2009) adalah kepuasan kerja terkait seberapa jauh karyawan puas dengan pekerjaan mereka. Hal ini sering terjadi dimana dua konsep dibahas bersama, karena dikatakan bahwa seseorang puas di tempat kerja sebagai ada faktor dan kondisi yang memotivasi dia. Robbins dan Judge (2011) menyatakan bahwa kepuasan kerja adalah perilaku umum untuk kinerja kerja sementara ada penghargaan dan prestasi yang tepat. Wexley dan Yukl (2005) menyatakan kepuasan kerja menunjukkan cara seorang karyawan merasakan tentang pekerjaannya.

Kepuasan kerja dosen adalah keadaan emosional dosen yang muncul dari cara mereka menilai pekerjaan mereka dan pengalaman (Nartey et al., 2018). Kepuasan kerja merupakan perasaan yang muncul sebagai akibat dari persepsi bahwa pekerjaan memungkinkan kebutuhan material dan psikologis (Aziri, 2011). Luthans (2010) menyatakan lima dimensi kepuasan kerja yaitu :pekerjaan itu sendiri, gaji, kesempatan promosi, pengawasan dan rekan kerja. Menurut Robbins dan Judge (2011), faktorfaktor yang berpengaruh terhadap kepuasan kerja adalah situasi kerja yang secara mental menantang, ganjaran yang pantas, kondisi kerja yang mendukung, rekan kerja yang mendukung, serta kesesuaian kepribadian dengan pekerjaan.

\section{Kerangka Pemikiran}

Pengaruh Kepuasan Kerja terhadap Kinerja

Hanaysha dan Tahir (2016) menyatakan bahwa kepuasan kerja sangat penting untuk aktualisasi diri karyawan. Seorang karyawan yang tidak mendapatkan kepuasan dalam pekerjaan maka tidak akan pernah mencapai kematangan psikologis, dan akhirnya akan menjadi frustrasi. Kepuasan kerja dapat diklasifikasikan secara singkat merupakan estimasi atau refleksi dari perasaan pekerja terhadap pekerjaannya (Jiang \& Rosenbloom, 2005).

Yap et al. (2012) menggambarkan kepuasan kerja sebagai hal yang positif atau sikap negatif yang dilakukan oleh seorang pribadi untuk pekerjaan mereka. Selain itu, kepuasan kerja juga sebagai cara berpikir, perasaan, dan tren tindakan seseorang sebagai sikap seseorang terhadap pekerjaan. Bentley et al. (2013) mengatakan kepuasan kerja sebagai kombinasi dari kondisi psikologis, fisiologis dan lingkungan yang menyebabkan seseorang jujur mengatakan puas dengan pekerjaannya.

Siahaan et al. (2016) berikutnya mempertegas bahwa kinerja itu perilaku nyata yang ditunjukkan oleh semua orang sebagai prestasi kerja yang diproduksi oleh seorang karyawan yang perannya ada di perusahaan bersama upaya untuk mencapai tujuan. Pandangan ini juga diperkuat oleh Samian dan Noor (2012) bahwa kinerja dapat dioptimalkan melalui penentuan deskripsi pekerjaan yang jelas dan ukuran untuk setiap petugas atau karyawan sehingga mereka mengerti apa fungsi mereka dan tanggung jawab. Beberapa penelitian sebelumnya mendukung kesimpulan bahwa pekerjaan itu kepuasan merupakan anteseden bagi kinerja (Jufrizen, 2016; Chung \& Kowalski, 2011; Arda, 2017; Gunawan et al., 2018). 


\section{Pengaruh Kepuasan Kerja terhadap Komitmen Organisasional}

Hubungan antara kepuasan kerja dan komitmen organisasional dapat terjadi ketika anggota organisasi memiliki level tinggi kepuasan dalam organisasi, sehingga mereka memiliki sikap percaya dan percaya pada, dan persepsi positif, organisasi. Sebuah kepuasan kerja karyawan dengan berbagai aspek pekerjaannya mengarah pada munculnya komitmen kuat pada organisasi. Seseorang yang merasa puas dengan mereka pekerjaan menunjukkan sikap dan perilaku positif terhadap organisasi. Pekerja yang puas menunjukkan komitmen yang lebih besar dibandingkan dengan pekerja yang tidak puas. Pekerja yang puas memiliki komitmen yang lebih besar, yang bisa dilihat dari rasa memiliki mereka terhadap organisasi.

Beberapa penelitian sebelumnya menyimpulkan bahwa kepuasan kerja merupakan anteseden bagi komitmen organisasional (Lok \& Crawford, 2001; Warsi et al., 2009; Zeinabadi, 2010; Ngadiman et al., 2013; Amos et al., 2015; Masyithah \& Eliana, 2019). Berdasarkan pemikiran yang telah diuraikan, dapat dihipotesiskan bahwa semakin tinggi kepuasan kerja dosen dalam berbagai aspek dari pekerjaannya, maka semakin tinggi komitmen organisasional yang dimiliki dosen.

\section{Pengaruh Komitmen Organisasional terhadap Kinerja}

Komitmen organisasi merupakan faktor penting dalam usaha untuk meningkatkan kinerja organisasi. Mowday et al. (1982) mendefinisikan komitmen organisasi sebagai kekuatan identifikasi individu dalam suatu organisasi melalui keinginan kuat untuk menjadi anggota organisasi terbaik untuk melibatkan dirinya dengan sepenuh hati mengerjakan pekerjaan, yang didasarkan pada penerimaan nilai-nilai organisasi dan tujuan.

Suliman dan Iles (2000) menemukan hubungan positif antara komitmen organisasional dan kinerja. Seseorang yang memiliki komitmen organisasional dapat dilihat dari keseriusannya dalam bekerja sebagai upaya untuk memberikan kontribusi maksimal bagi pengembangan organisasi. Ketulusan dalam bekerja adalah manifestasi dari penerimaan dan kepatuhan seseorang terhadap visi, misi dan tujuan yang ditetapkan oleh organisasi dan keinginannya untuk tetap menjadi anggota organisasi (Mowday et al., 1982). Beberapa penelitian sebelumnya telah menunjukkan komitmen organisasional berkontribusi positif terhadap kinerja (Khan et al., 2010; Dinantara, 2018; Hafid \& Fajariani, 2019).

Berdasarkan uraian variabel-variabel tersebut, kerangka pemikiran dalam penelitian ini dapat ditunjukkan seperti Gambar 1. Rumusan hipotesis yang diajukan dalam penelitian berdasarkan kerangka pemikiran tersebut adalah:

H1 : Kepuasan kerja berpengaruh secara signifikan terhadap komitmen organisasional dosen.

H2 : Kepuasan kerja berpengaruh secara signifikan terhadap kinerja dosen.

H3 : Komitmen organisasional berpengaruh secara signifikan terhadap kinerja dosen.

H4: Komitmen organisasional memediasi pengaruh kepuasan kerja terhadap kinerja dosen. 


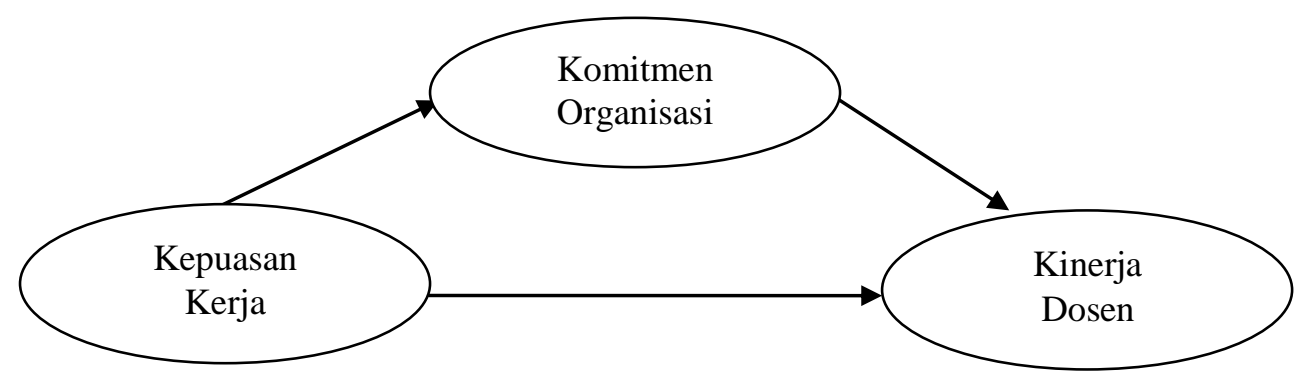

\section{Gambar 1. Kerangka Pemikiran}

Sumber: Diolah penulis, 2019.

\section{METODE PENELITIAN}

Penelitian ini adalah pendekatan asosiatif. Lokasi penelitian adalah di Universitas Muhammadiyah Sumatera Utara (UMSU) dan Universitas Muslim Nusantara (UMN) Al Washliyah yang terletak di Kota Medan.

Populasi adalah seluruh dosen tetap Universitas Muhammadiyah Sumatera Utara (UMSU) dan Universitas Muslim Nusantara (UMN) Al Washliyah yang berjumlah 485 orang dan yang memiliki jabatan fungsional dari Asisten Ahli sampai Lektor Kepala, dan memenuhi kriteria: (1) berdomisili di Medan; (2) memiliki masa kerja di atas 2 tahun; dan, (3) melaksanakan Tri Dharma Perguruan Tinggi. Jumlah populasi penelitian ditunjukkan pada Tabel 1.

Tabel 1. Populasi Penelitian

\begin{tabular}{ccc}
\hline No & PTS & Jumlah Dosen \\
\hline 1 & UMSU & 370 \\
2 & UMN & 115 \\
\hline & Jumlah & 485 \\
\hline
\end{tabular}

Sumber: Diolah penulis, 2019.

Untuk menentukan jumlah sampel, digunakan rumus Slovin (Umar, 2000) sebagai berikut:

$$
\mathrm{n}=\frac{N}{1+N e^{2}}
$$

Jika populasi $(\mathrm{N})$ sebanyak 485 orang dan taraf kesalahan (e) sebesar 5\%, maka besarnya sampel (n) adalah :

$$
\mathrm{n}=\frac{485}{1+485\left(0,05^{2}\right)}=219 \text { orang }
$$

Pengambilan sampel dalam penelitian memakai proportional random sampling. Dua buah Universitas Islam Swasta di Kota Medan diteliti dimana jumlah dosen tetapnya di setiap universitas tersebut tidak sama, maka sampel yang diambil secara proporsi berdasarkan jumlah dosen yang ada di universitas masing-masing.

Pengumpulan data dilakukan dengan dua metode, yaitu wawancara dan kuesioner. Wawancara dilakukan dengan berkomunikasi secara langsung pada responden, maupun pihak-pihak yang terkait seperti Wakil Rektor I, Dekan dan Wakil Dekan I serta Lembaga Penelitian, Pengembangan dan Pengabdian Masyarakat (LP3M) dengan model tidak terstruktur atau bebas. Metode berikutnya adalah dengan memberikan kuesioner kepada pihak yang terpilih sebagai responden yang berisi tentang persepsi dosen berkaitan dengan kepuasan kerja, komitmen organisasional dan kinerja dosen.

Variabel penelitian ini terdiri dari tiga jenis, yakni variabel eksogenus, endogenus, serta intervening. Variabel eksogenus adalah kepuasan kerja, yang didefinisikan sebagai keadaan emosi dosen yang bersifat positif maupun menyenangkan yang dihasilkan dari penilaian suatu pekerjaan atau pengalaman ((Luthans, 2010). Variabel endogenus adalah kinerja dosen, yang didefinisikan sebagai 
kemampuan dosen untuk melaksanakan pekerjaan atau tugas yang diemban dan memiliki kemampuan dalam menyelesaikan pekerjaan (Trisnaningsih, 2011). Variabel intervening adalah komitmen organisasional, yang merupakan usaha mendefinisikan dan melibatkan diri dalam organisasi dan tidak ada keinginan meninggalkannya (Robbins \& Judge, 2011).

Data penelitian yang terkumpul berikutnya dianalisis menggunakan metode analisis jalur (Path Analysis). Proses analisis data dilakukan dengan bantuan program SPSS for Windows versi 19.0.

\section{HASIL ANALISIS}

Penelitian ini menggunakan analisis jalur (path analysis). Persamaan model analisis jalur dalam penelitian ini adalah:

$$
\begin{aligned}
& \mathrm{KOM}=0,371 \mathrm{KEP}+\varepsilon_{1} \\
& \mathrm{KIN}=0,371 \mathrm{KEP}+0,279 \mathrm{KOM}+\varepsilon_{2}
\end{aligned}
$$

Nilai-nilai koefisien yang terlihat di dalam Gambar 2 memperlihatkan pengaruh langsung dan tidak langsung antar-variabel di dalam penelitian ini.
Hasil pertama yang diperoleh menunjukkan bahwa pengaruh langsung (direct effect) dari kepuasan kerja (KEP) terhadap kinerja dosen (KIN) memiliki nilai koefisien jalur $\left(\mathrm{p}_{1}\right)$ sebesar 0,279 dan nilai probabilitas (Sig.) sebesar $0,000<0,05(\alpha)$. Nilai yang positif dan signifikan tersebut bermakna jika nilai kepuasan kerja dosen tinggi maka kinerja dosen juga tinggi.

Hasil kedua yang diperoleh menunjukkan pengaruh langsung (direct effect) dari kepuasan kerja (KEP) terhadap komitmen organisasional (KOM) memiliki nilai koefisien jalur $\left(\mathrm{p}_{2}\right)$ sebesar 0,371 dan nilai probabilitas (Sig.) sebesar 0,002 $<0,05(\alpha)$. Nilai yang positif dan signifikan itu bermakna jika tingkat kepuasan kerja dosen tinggi maka komitmen organisasional dosen juga tinggi.

Hasil ketiga yang diperoleh menunjukkan bahwa pengaruh langsung (direct effect) dari komitmen organisasional (KOM) pada kinerja dosen (KIN) memiliki nilai koefisien jalur $\left(\mathrm{p}_{3}\right)$ sebesar 0,279 dan nilai probabilitas (sig) sebesar $0,000<0,05(\alpha)$. Nilai yang positif dan signifikan tersebut bermakna jika komitmen organisasional dosen tinggi maka kinerja dosen akan tinggi.

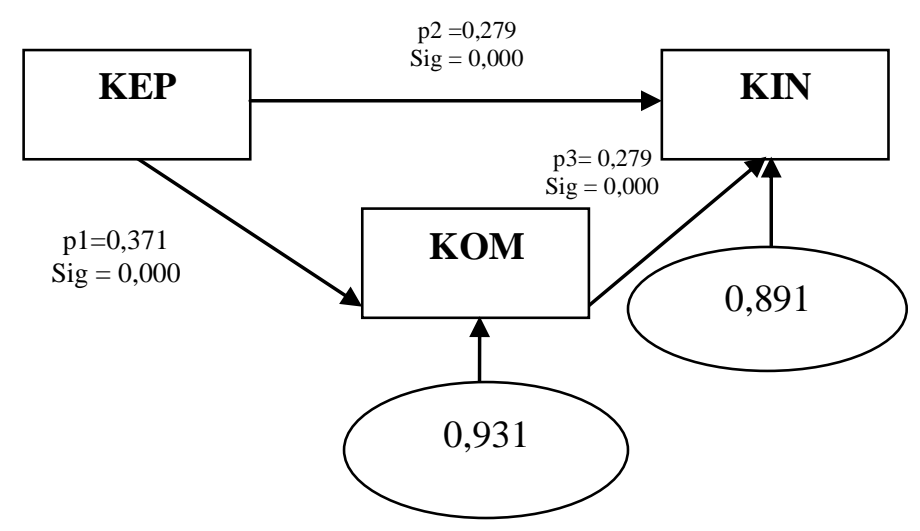

\section{Gambar 2. Model Analisis Jalur (Path Analysis)}

Sumber: Data primer diolah, 2019.

Hasil keempat yang diperoleh menunjukkan bahwa pengaruh tidak langsung (indirect effect) dari kepuasan kerja (KEP) terhadap kinerja dosen (KIN) melalui mediasi oleh komitmen organisasional (KOM) adalah sebesar $\mathrm{p}_{1}(0,371) \times \mathrm{p}_{3}(0,279)=0,104$. Sementara pengaruh langsung (direct effect) dari kepuasan kerja (KEP) terhadap kinerja 
dosen (KIN) sebesar $\mathrm{p}_{2}=0,279$. Dengan demikian, nilai koefisien pengaruh tidak langsung $(0,104)<$ nilai koefisien pengaruh langsung (0,279). Perbandingan tersebut bermakna bahwa komitmen organisasional (KOM) tidak berperan sebagai mediator dalam jalur pengaruh dari kepuasan kerja terhadap kinerja dosen.

\section{Pembahasan}

\section{Pengaruh Kepuasan Kerja terhadap Kinerja Dosen}

Berdasarkan hasil pengolahan data, diketahui bahwa variabel kepuasan kerja berpengaruh positif dan signifikan terhadap kinerja dosen. Dengan demikian dapat disimpulkan bahwa semakin tinggi kepuasan kerja yang dirasakan dosen tetap Universitas Islam Swasta di Kota Medan, maka kinerja dosennya akan semakin baik pula.

Teori menyatakan bahwa hubungan antara kepuasan kerja dan prestasi kerja telah ditetapkan dengan kuat dalam sejumlah literatur perilaku organisasi (Barakat et al., 2015). Hasil penelitian milik Jufrizen (2016) menunjukkan kepuasan kerja berpengaruh terhadap kinerja. Hasil penelitian ini sejalan dengan beberapa penelitian sebelumnya yang menyimpulkan kepuasan kerja merupakan faktor anteseden bagi kinerja (Bangun et al., 2018; Chung \& Kowalski, 2011; Gunawan et al., 2018; Werang \& Agung, 2017; Gani et al., 2018; Kawiana et al., 2018; Koesmono, 2014).

\section{Pengaruh Kepuasan Kerja terhadap Komitmen Organisasional}

Berdasarkan hasil pengolahan data, diketahui bahwa variabel kepuasan kerja berpengaruh positif dan signifikan terhadap komitmen organisasional dosen. Karenanya dapat disimpulkan bahwa semakin tinggi kepuasan kerja yang dirasakan dosen, maka komitmen organisasionalnya akan semakin baik pula.

Hasil penelitian ini sejalan dengan hasil penelitian milik Malik et al. (2010) yang menyimpulkan kepuasan kerja memiliki pengaruh positif dan signifikan terhadap komitmen organisasional. Hasil penelitian Anisykurlillah et al. (2013) juga menyatakan semua aspek kepuasan kerja ditemukan berkorelasi positif dan kuat dengan komitmen organisasional. Sedangkan hasil penelitian dari Muis et al. (2018) menyimpulkan bahwa kepuasan kerja memiliki pengaruh terhadap komitmen organisasional.

Hasil penelitian ini juga sejalan dengan sejumlah penelitian terdahulu yang menyatakan kesimpulan bahwa kepuasan kerja sebagai anteseden bagi komitmen organisasional (Zeinabadi, 2010; Ngadiman et al., 2013; Srivastava, 2013; Amos et al., 2015; Jufrizen, 2015; Werang \& Agung, 2017; Chalim, 2018; Gani et al., 2018; Koesmono, 2014; Berlian, 2018).

\section{Pengaruh Komitmen Organisasional terhadap Kinerja Dosen}

Berdasarkan hasil pengolahan data dari model struktural, diketahui bahwa variabel komitmen organisasional berpengaruh positif terhadap kinerja dosen secara signifikan. Dengan demikian, dapat disimpulkan bahwa semakin tinggi komitmen organisasional dari dosen tetap Universitas Swasta di Kota Medan, maka kinerja dosennya akan semakin baik pula.

Secara teoritis, kepuasan kerja memiliki hubungan dengan kinerja. Hettiararchchi \& Jayarathna (2014) menyatakan bahwa seorang individu dengan komitmen organisasional yang tinggi akan menunjukkan perilaku positif kepada organisasi, memberikan yang terbaik yang dia bisa, pengorbanan, memiliki tingkat loyalitas yang tinggi pada organisasi, dan juga memiliki kesediaan untuk tetap 
dalam organisasi. Hasil penelitian Suhana (2007), Suliman (2002), dan Muis et al. (2018) juga menyimpulkan bahwa komitmen organisasional berpengaruh terhadap kinerja.

Hasil penelitian ini didukung beberapa penelitian sebelumnya yang menunjukkan bahwa komitmen organisasional berkontribusi positif terhadap kinerja (Khan et al., 2010; de Araújo \& Lopes, 2014; Romadhona \& Wahyuningtyas, 2019; Malik, et al., 2010; Laily \& Wahyuni, 2017; Pardiman, 2018; Akhtar et al., 2015; Kawiana et al., 2018).

\section{SIMPULAN}

Berdasarkan hasil dari penelitian ini, maka dapat disimpulkan bahwa kepuasan kerja terbukti berpengaruh secara langsung dan signifikan terhadap komitmen organisasional, komitmen organisasional terbukti berpengaruh langsung dan signifikan terhadap kinerja dosen, dan terbukti adanya pengaruh langsung secara signifikan dari kepuasan kerja terhadap kinerja dosen. Namun demikian, hasil penelitian ini menunjukkan bahwa kepuasan kerja tidak berpengaruh terhadap kinerja dosen melalui mediasi oleh komitmen organisasional.

Hasil-hasil penelitian ini mendasari rekomendasi utama yang dapat diberikan, yaitu bahwa dalam upaya membangun kepuasan kerja, komitmen organisasional dan kinerja dosen, maka pihak pimpinan universitas swasta seharusnya memperhatikan kebijakan ataupun administrasi dari organisasi, supervisi, kondisi kerja, hubungan antarpersonal, serta gaji dan promosi, supaya tercipta peningkatan kinerja dosen.

Keterbatasan utama dari penelitian ini adalah hanya dilakukan pada dua universitas swasta di Kota Medan. Karenanya direkomendasikan bagi para peneliti berikutnya untuk dapat melaksanakan upaya penelitian serupa pada lingkup yang lebih luas meliputi semua universitas swasta yang ada di Kota
Medan. Selain itu, bagi peneliti selanjutnya, sebaiknya menambah variabel lain ataupun memperhitungkan efek moderasi variabel lain, sehingga bias diidentifikasi lebih banyak faktor yang dinilai memiliki pengaruh atas komitmen organisasional dan kinerja dosen.

\section{REFERENSI}

Ahmad, R., Shafique, M., Ahmed, K., Saleem, S.S. \& Imam, A. 2015. Relationship of Job Satisfaction and Organizational Commitment with Stay Intention of Faculty of Higher Education Institutes: The Moderating Role of Work-Family Conflict \& Family-Work Conflict. Vidyabharati International Interdisciplinary Research Journal. 4(1): 19-33.

Akhtar, A., Durrani, A.B. \& Hassan, W. 2015. The Impact of Organizational Commitment on Job Satisfaction and Job Performance: An Empirical Study from Pakistan. IOSR Journal of Business and Management (IOSRJBM). 17(6): 75-80.

Akpan, C.P. 2013. Job Security and Job Satisfaction as Determinants of Organizational Commitment Among University Teachers in Cross River State, Nigeria. British Journal of Education. 1(2): 82-93.

Amos, P.M., Acquah, S., Antwi, T. \& Adzifome, N.S. 2015. A Comparative Study of Factors Influencing Male and Female Lecturers' Job Satisfaction in Ghanaian Higher Education. Journal of Education and Practice. 6(4): 1-10.

Anggraeni, R.D. 2013. Increasing Lecturer Competence as the Quality Assurance of Lecturer Performance. Proceedings of 7th Global Business and Social Science Research Conference. https://wbiworldconpro.com/uploads/chi na-conference-2013/management/ 1370754128_404-Rinny.pdf.

Anisykurlillah, I., Wahyudin, A. \& Kustiani. 2013. Pengaruh Role Stressor terhadap Komitmen Organisasi dengan Kepuasan Kerja sebagai Variabel Intervening pada 
Kantor Akuntan Publik (KAP) di Jawa Tengah. Jurnal Dinamika Akuntansi. 5(2): 109-120.

de Araújo, M.S.G. \& Lopes, P.M.P.R. 2014. Virtuous Leadership, Organi-zational Commitment and Individual Performance. Tékhne. 12(1): 3-10.

Arda, M. 2017. Pengaruh Kepuasan Kerja dan Disiplin Kerja terhadap Kinerja Karyawan pada Bank Rakyat Indonesia Cabang Putri Hijau Medan. Jurnal Ilmiah Manajemen dan Bisnis. 18(1): 45-60.

Arifin, N. 2012. Analisis Kualitas Kehidupan Kerja, Kinerja, dan Kepuasan Kerja pada CV. Duta. Jurnal Economia. 8(1): $11-21$.

Aziri, B. 2011. Job Satisfaction: A Literature Review. Management Research and Practice. 3(4): 77-86.

Baldwin, J.D. \& Baldwin, J.I. 2009. Behavior Principles in Organization Everyday Life. $4^{\text {th }}$ eds. Upper Saddle River, N.J: Prentice Hall.

Bangun, R., Theresia, L., Lahuddin, A.H. \& Ranti, G. 2018. The Influence of Culture, Job Satisfaction and Motivation on the Performance Lecturer/ Employees. Proceedings. International Confe rence on Industrial Engineering and Operations Management: 2541-2552.

Barakat, L.L., Lorenz, M.P., Ramsey, J.R. \& Ramsey, J.R. 2015. Global Managers: An Analysis of the Impact of Cultural Intelligence on Job Satisfaction and Performance. International Journal of Emerging Market. 10(4): 781-800.

Bentley, P.J., Coates, H., Dobson, I.R., Goedegebuure, L. \& Meek, V.L. 2013. Factors Associated with Job Satisfaction Amongst Australian University Academics and Future Workforce Implications. Job Satisfaction around the Academic World: 29-53.

Berlian, Z. 2018. Competency Analysis of Job Satisfaction and Organizational Commitment to Lecturers Who Teach at Private Universities in the Area of Southern Sumatra. American Research
Journal of Business and Management. 4(1): 1-6.

Chalim, A.S. 2018. Effect of Job-Insecurity, Organizational Commitment, Job Satisfaction on Turnover Intention: A Case Study of Newcomer Lecturers at Private Islamic Universities in East Java Province, Indonesia. Jurnal Ilmiah Peuradeun. 6(2): 199-214.

Chung, C.E. \& Kowalski, S. 2011. Job Stress, Mentoring, Psychological Empowerment, and Job Satisfaction among Nursing Faculty. Journal of Nursing Education. 51(7): 381-388.

Curtis, S. \& Wright, D. 2001. Retaining Employees - The Fast Track to Commitment. Management Research News. 24(8/9): 59-64.

Dinantara, M.D. 2018. The Influence of Organizational Commitment and Motivation on Lecturer Performance of Pamulang University. Scientific Journal of Reflection: Economic, Accounting, Management and Bussines. 1(1): 71-80.

Eliyana, A., Ma'arif, S. \& Muzakki. 2019. Job Satisfaction and Organizational Commitment Effect in the Transformational Leadership towards Employee Performance. European Research on Management and Business Economics. https://doi.org/ 10.1016/j.iedeen. 2019.05.001

Furnham, A., Eracleous, A. \& ChamorroPremuzic, T. 2009. Personality, Motivation and Job Satisfaction: Hertzberg meets the Big Five. Journal of Managerial Psychology. 24(8): 765779.

Gani, H.M.U., Nur, M., Mallongi, H.S. \& Rusjdin, H. 2018. The Impacts of Competence, Work Motivation, Job Satisfaction and Organizational Commit ment on Lecturers' Performance. IRAInternational Journal of Management \& Social Sciences. 11(1): 17-25.

Griffin, M.L., Hogan, N.L., Lambert, E.G., Tucker-Gail, K.A. \& Baker, D.N. 2009. Job Involvement, Job Stress, Job 
Satisfaction, and Organizational Commitment and the Burnout of Correctional Staff. Criminal Justice and Behavior. 37(2): 239-255.

Gunawan, A., Barasa, L. \& Tua, H. 2018. Determinant of Lecturers Work Satisfaction and Implication on Lecturers Performance at Maritime Higher Education in DKI Jakarta. International Review of Management and Marketing. 8(4): 14-23.

Hafid, H. \& Fajariani, N. 2019. Hubungan Profesionalisme, Komitmen Organisasi dan Kinerja Dosen pada STIE Muhammadiyah Mamuju. Kinerja. 16(1): 58-68.

Hanaysha, J. \& Tahir, P.R. 2016. Examining the Effects of Employee Empowerment, Teamwork, and Employee Training on Job Satisfaction. Procedia - Social and Behavioral Sciences. 219: 272-282.

He, P., Murmann, S.K. \& Perdue, R.R. 2012. Management Commitment and Employee Perceived Service Quality: The Mediating Role of Affective Commitment. Journal of Applied Management and Enterpreneurship. 17(3): 79-97.

Hettiararchchi, H.A.H. \& Jayarathna, S.M.D. 2014. The Effect of Employee Work Related Attitudes on Employee Job Performance: A Study of Tertiary and Vocational Education Sector in Sri Lanka. IOSR Journal of Business and Management (IOSR-JBM). 16(4): 7483.

Hidayati, T. \& Rahmawati. 2016. The Effect on the Job Satisfaction Organization, Performance of Employees Commitment, and Service Performance. Kinerja: Jurnal Ekonomi Dan Manajemen. 13(1): 1-12.

Imran, H., Arif, I., Cheema, S. \& Azeem, M. 2014. Relationship between Job Satisfaction, Job Performance, Attitude Towards Work, and Organizational Commitment. Entrepreneurship and Innovation Management Journal. 2(2): 135-144.
Jiang, P. \& Rosenbloom, B. 2005. Customer Intention to Return Online: Price Perception, Attribute-Level Performance, and Satisfaction Unfolding Overtime. European Journal of Marketing. 39(1/2): 150-170.

Jufrizen, J. 2015. Pengaruh Kompensasi dan Pengembangan Karir terhadap Komitmen Organisasi dengan Kepuasan Kerja sebagai Variabel Intervening pada PT. Perkebunan Nusantara III (Persero) Medan. Jurnal Ilmiah Manajemen dan Bisnis. 15(1): 37-47.

Jufrizen, J. 2016. Efek Mediasi Kepuasan Kerja pada Pengaruh Kompensasi terhadap Kinerja Karyawan. Jurnal Ilmiah Manajemen dan Bisnis. 17(1): 1-18.

Kaplan, R.S. \& Norton, D.P. 2006. The Strategy-Focused Organization: How Balanced Scorecard Companies Thrive in the New Business Environment. New York: Harvard Business Review Press.

Kartini, Sujanto, B. \& Mukhtar, M. 2017. The Influence of Organizational Climate, Transformational Leadership, and Work Motivation on Teacher Job Performance. International Journal of Human Capital Management. 1(1): 192-2015.

Kawiana, G.P., Dewi, L.K.C., Martini, L.K.B. \& Suardana, I.B.R. 2018. The Influence of Organizational Culture, Employee Satisfaction, Personality, and Organizational Commitment towards Employee Performance. International Research Journal of Management, IT \& Social Sciences. 5(3): 35-45.

Khan, M.R., Ziauddin, Jam, F.A. \& Ramay, M.I. 2010. The Impacts of Organizational Commitment on Employee Job Performance. European Journal of Social Sciences. 15(3): 292-298.

Koesmono, H.T. 2014. The Influence of Organizational Culture, Servant Leadership, and Job Satisfaction Toward Organizational Commitment and Job Performance Through Work Motivation as Moderating Variables for Lecturers in 
Economics and Management of Private Universities in East. Educational Research International. 3(4): 25-39.

Koontz, H. \& Weihrich, H. 2010. Essentials of Management. New Delhi: McGraw Hill, Inc.

Kreitner, R. \& Kinicki, A. 2013. Perilaku Organisasi (Organizational Behavior). Edisi 9. Jakarta: Salemba Empat.

Laily, N. \& Wahyuni, D.U. 2017. Teacher Performance Based on Stress and Organizational Commitment. International Journal of Scientific and Research Publications. 7(12): 192199.

Lok, P. \& Crawford, J. 2001. Antecedents of Organizational Commitment and the Mediating Role of Job Satisfaction. Journal of Managerial Psychology. 16(8): 594-613.

Luthans, F. 2010. Organizational Behavior : An Evidence-Based Approach. 12th ed. New York: McGraw-Hill/Irwin.

Malik, M.E., Nawab, S., Naeem, B. \& Danish, R.Q. 2010. Job Satisfaction and Organizational Commitment of University Teachers in Public Sector of Pakistan. International Journal of Business and Management. 5(6): 1726.

Masyithah, S.M. \& Eliana, E. 2019. Model Peningkatan Loyalitas Kerja Dosen PTS Menggunakan Structural Equation Modeling. Jurnal Samudra Ekonomi dan Bisnis. 10(2): 179-192.

Meyer, J.P., Stanley, D.J., Herscovitch, L. \& Topolnytsky, L. 2002. Affective, Continuance, and Normative Commitment to the Organization: A Meta-Analysis of Antecedents, Correlates, and Consequences. Journal of Vocational Behavior. 61(1): 20-52.

Mowday, R.T., Porter, L.W. \& Steers, R.M. 1982. Employee-Organizational Linkages: The Psychology of Commit ment, Absenteeism and Turnover. New York: Academic Press.
Muchinsky, P.M. \& Howes, S.S. 2019. Psychology Applied to Work: An Introduction to Industrial and Organizational Psychology. $12^{\text {th }}$ ed. North Carolina: Hypergraphic Press, Incorporated.

Muis, M.R., Jufrizen, J. \& Fahmi, M. 2018. Pengaruh Budaya Organisasi dan Komitmen Organisasi terhadap Kinerja Karyawan. Jesya (Jurnal Ekonomi \& Ekonomi Syariah). 1(1): 9-25.

Na, J., Amzat, I.H. \& Abolhaija, J.H. 2011. A Study of Lecturers Job Satisfaction in Selected Harbin City Universities, China. Interdisciplinary Journal of Contemporary Research in Business. 3(1): 17-39.

Narasuci, W., Setiawan, M. \& Noermijati. 2018. Effect of Work Environment on Lecturer Performance Mediated by work Motivation and Job Satisfaction. Journal of Applied Management (JAM). 16(4): 645-653.

Nartey, L.T., Annan, A. \& Nunoo, T.E. 2018. The Interacting Role of Organi-zational Support and Job Satisfaction on Teacher Commitment: Evidence from Colleges of Education in Ghana. International Journal of Education and Research. 6(8): 57-74.

Ngadiman, Eliyana, A. \& Ratmawati, D. 2013. Influence of Transformational Leadership and Organization Climate to the Work Satisfaction, Organizational Commitment and Organizational Citizenship Behavior on the Educational Personnel of Sebelas Maret University, Surakarta. European Journal of Business and Management. 5(10): 97-114.

Pardiman. 2018. The Effect of Social Capital and Organizational Commitment toward Lecturer Performance with Islamic Work Ethics as a Moderating Role. Jurnal Ilmiah Bidang Akuntansi dan Manajemen (JEMA). 15(1): 12-26.

Reyes, P. \& Shin, H.-S. 1995. Teacher Commitment and Job Satisfaction: A Causal Analysis. Journal of School Leadership. 5(1): 22-39. 
Robbins, S.P. \& Judge, T.A. 2011. Organizational Behavior. $14^{\text {th }}$ ed. New Jersey: Prentice Hall.

Romadhona, A.F. \& Wahyuningtyas, R. 2019. Komitmen dan Budaya Organisasi terhadap Kinerja Karyawan Bank BJB Cabang Tamansari. Jurnal Riset Bisnis Dan Manajemen. 12(1): 24-30.

Rose, R.C., Kumar, N. \& Pak, O.G. 2009. The Effect of Organizational Learning on Organizational Commitment, Job Satisfaction and Work Performance. Journal of Applied Business Research. 25(6): 55-65.

Samian, Y. \& Noor, N.M. 2012. Student's Perception on Good Lecturer Based on Lecturer Performance Assessment. Procedia - Social and Behavioral Sciences. 56: 783-790.

Santos, A.S., Neto, M.T.R. \& Verwaal, E. 2018. Does Cultural Capital Matter for Individual Job Performance? A LargeScale Survey of the Impact of Cultural, Social and Psychological Capital on Individual Performance in Brazil. International Journal of Productivity and Performance Management. 67(8): 1352-1370.

Schultz, D.P. \& Schultz, S.E. 2015. Psychology and Work Today. 10th ed. New Jersey: Pearson New International Edition.

Siahaan, E., Gultom, P. \& Lumbanraja, P. 2016. Improvement of Employee Banking Performance Based on Competency Improvement and Placement Working through Career Development (Case Study in Indonesia). International Business Management. 10(3): 255-261.

Simanjuntak, P.J. 2011. Manajemen \& Evaluasi Kerja. $3^{\text {rd }}$ ed. Jakarta: LPFE Universitas Indonesia.

Sopiah. 2008. Perilaku Organisasi. Yogyakarta: Andi Offset.

Spector, P.E. 2009. Industrial and Organizational Psychology: Research and Practice. New York, NY: John Wiley \& Sons Inc.
Srivastava, S. 2013. Job Satisfaction and Organizational Commitment Relationship: Effect of Personality Variables. Vision: The Journal of Business Perspective. 17(2): 159-167.

Suhana. 2007. Relationship Analysis of Leadership Style, HRM Practices, Organizational Culture, Commitment and Performance (Study in People Crediting Bank (BPR) in Central Java. Usahawan. 36(10): 47-53.

Sukirno, D.S. \& Siengthai, S. 2011. Does Participative Decision Making Affect Lecturer Performance in Higher Education? International Journal of Educational Management. 25(5): 494508.

Suliman, A.M. \& Iles, P.A. 2000. The MultiDimensional Nature of Organiza-tional Commitment in a Non-Western Context. Journal of Management Development. 19(1): 71-83.

Suliman, A.M.T. 2002. Is It Really a Mediating Construct? The Mediating Role of Organizational Commitment in Work Climate Performance Relationship. Journal of Management Development. 21(3): 170-183.

Tangkilisan, H.N.S. 2005. Manajemen Publik. Jakarta: Grasindo.

Trisnaningsih, S. 2011. Faktor-Faktor yang Mempengaruhi Kinerja Dosen Akuntansi. Jurnal Akuntansi \& Auditing. 8(1): 83-94.

Umar, H. 2000. Riset Pemasaran Dan Penilaian Konsumen. Jakarta: PT Gramedia Pustaka Utama.

Warsi, S., Fatima, N. \& Sahibzada, S.A. 2009. Study on Relationship between Organizational Commitment and Its Determinants among Private Sector Employees of Pakistan. International Review of Business Research Papers. 5(3): 399-410.

Werang, B.R. \& Agung, A.A.G. 2017. Teachers' Job Satisfaction, Organizational Commitment, and Performance in Indonesia: A Study from Merauke District, Papua. International Journal 
of Development and Sustainability. 6(8): 700-711.

Wexley, K.N. \& Yukl, G.A. 2005. Perilaku Organisasi dan Psikologi Personalia. Jakarta: Rineka Cipta.

Whiteford, P. 1990. Differences between Teachers Who Have and Have Not Taught Continuously During the First Five Years After Graduation. The Annual Meeting of the American Educational Research Association. Chicago, IL.

Wijatno, S. 2009. Pengelolaan Perguruan Tinggi Secara Efisien, Efektif dan Ekonomis. Jakarta: Salemba Empat.

Wu, L. \& Norman, I.J. 2006. An Investigation of Job Satisfaction, Organizational Commitment and Role Conflict and Ambiguity in a Sample of Chinese Undergraduate Nursing Students. Nurse Education Today. 26: 304-314.
Yap, B.W., Ramayah, T. \& Shahidan, W.N.W. 2012. Satisfaction and Trust on Customer Loyalty: A PLS Approach. Business Strategy Series. 13(4): 154167.

Yousef, D.A. 2000. Organizational Commitment as a Mediator of the Relationship between Islamic Work Ethic and Attitudes toward Organizational Change. Human Relations. 53(4): 513537.

Zeinabadi, H. 2010. Job Satisfaction and Organizational Commitment as Antecedents of Organizational Citizenship Behavior (OCBS) of Teachers. Procedia - Social and Behavioral Sciences. 5: 998-1003. 